Article

\title{
Inhibition of Cell Survival by Curcumin Is Associated with Downregulation of Cell Division Cycle 20 (Cdc20) in Pancreatic Cancer Cells
}

\author{
Yu Zhang ${ }^{1,+}$, Ying-bo Xue ${ }^{1,+}{ }^{,}$Hang Li $^{1}$, Dong Qiu ${ }^{1}$, Zhi-wei Wang ${ }^{2, *}$ and Shi-sheng Tan ${ }^{1, *}$ \\ 1 Department of Oncology, Guizhou People’s Hospital, Guizhou 550002, China; skyline_zyu@163.com (Y.Z.); \\ xueyingbo0619@163.com (Y.-b.X.); lihang.sy@163.com (H.L.); qiudcds@126.com (D.Q.) \\ 2 Department of Pathology, Beth Israel Deaconess Medical Center, Harvard Medical School, Boston, \\ MA 02215, USA \\ * Correspondence: zwang6@bidmc.harvard.edu (Z.-w.W.); tssh18018@126.com (S.-s.T.) \\ + These authors contributed equally to this work.
}

Received: 22 November 2016; Accepted: 25 January 2017; Published: 4 February 2017

\begin{abstract}
Pancreatic cancer is one of the most aggressive human tumors in the United States. Curcumin, a polyphenol derived from the Curcuma longa plant, has been reported to exert its antitumor activity in pancreatic cancer. However, the molecular mechanisms of curcumin-mediated tumor suppressive function have not been fully elucidated. In the current study, we explore whether curcumin exhibits its anti-cancer function through inhibition of oncoprotein cell division cycle 20 (Cdc20) in pancreatic cancer cells. We found that curcumin inhibited cell growth, enhanced apoptosis, induced cell cycle arrest and retarded cell invasion in pancreatic cancer cells. Moreover, we observed that curcumin significantly inhibited the expression of Cdc20 in pancreatic cancer cells. Furthermore, our results demonstrated that overexpression of Cdc20 enhanced cell proliferation and invasion, and abrogated the cytotoxic effects induced by curcumin in pancreatic cancer cells. Consistently, downregulation of $\mathrm{Cdc} 20$ promoted curcumin-mediated anti-tumor activity. Therefore, our findings indicated that inhibition of Cdc20 by curcumin could be useful for the treatment of pancreatic cancer patients.
\end{abstract}

Keywords: curcumin; Cdc20; pancreatic cancer; growth; invasion

\section{Introduction}

Pancreatic cancer (PC) is one of the most highly aggressive malignancies in humans. According to the American Cancer Society, there will be 53,670 estimated new cases and 43,090 deaths due to PC in the United States in 2017 [1]. The routine treatments include surgery, radiation and chemotherapy. Although multiple-treatment approaches have been improved, the outcomes of PC patients are still poor. Because PC patients are diagnosed at a late stage and exhibit acquired drug resistance during chemotherapeutic treatment, the 5-year relative survival of PC is currently $7 \%$ [1]. Therefore, it is essential to find new agents to improve the treatment outcome in patients with PC.

Emerging evidence has supported that curcumin, a golden pigment extracted from turmeric, exhibits anti-tumor properties in various types of human cancers including PC [2-5]. For example, one study showed that curcumin inhibited interleukin 8 production in PC cells [6]. Moreover, it has been reported that curcumin suppressed cell proliferation and induced apoptosis through inhibition of nuclear factor-kappa B (NF-kB) and IkappaB (IкB) kinase in PC cells [7,8]. Further study found that curcumin synergistically potentiated the growth inhibitory and pro-apoptotic effects of celecoxib in PC cells [9]. Consistently, curcumin potentiates anticancer activity of gemcitabine via inhibition of proliferation, angiogenesis, and suppression of the NF-KB pathway in an orthotopic model of 
PC [10]. Notably, curcumin inhibited PC cell proliferation via downregulation of cyclooxygenase-2 (COX-2), epidermal growth factor receptor (EGFR) and extracellular signal regulated kinase (ERK1/2) signaling pathways [11]. Sahu et al. found that curcumin activated ataxia telangiectasia mutated (ATM)/check point kinase-1 (Chk1), leading to cell cycle arrest and apoptosis in human PC cells [12]. One study identified that Wilms' tumor gene 1 (WT1) is one target of curcumin in PC cells [13]. Another study validated that curcumin inhibited constitutive signal transducer and activator of transcription 3 (STAT3) phosphorylation and down-regulated survivin/baculoviral inhibitor of apoptosis repeat-containing 5 (BIRC5) expression in PC cells [14]. Sun et al. reported that curcumin reversed the epithelial-mesenchymal transition through inhibition of the Hedgehog signaling pathway in PC cells [15]. Although these reports identified the molecular basis of curcumin-triggered tumor suppression, the underlying molecular mechanisms are still not clear.

Emerging evidence has revealed that cell division cycle 20 (Cdc20), an activator of the ligase anaphase-promoting complex/C (APC/C), plays an oncogenic role in tumorigenesis [16]. Higher expression of $\mathrm{Cdc} 20$ has been observed in a variety of human cancers and is correlated with poor prognosis [17-19]. For instance, patients with glioblastomas exhibited upregulation of Cdc20, while low-grade glioma patients have downregulation of Cdc20 [20]. Kim et al. found that Cdc20 was upregulated in high-grade squamous intraepithelial lesions and squamous cell carcinomas of the uterine cervix [17]. Similarly, increased Cdc20 expression is associated with development and progression of hepatocellular carcinoma [21]. Cdc20 and securin overexpression predicted short-team breast cancer survival [22]. Consistently, high Cdc20 expression is associated with poor prognosis in oral squamous cell carcinoma [18], gastric cancer [23], urothelial bladder cancer [24], colorectal cancer [19], non-small cell lung cancer [25], and pancreatic cancer [26]. In the current study, we explored whether Cdc20 exerts its oncogenic effects on cell growth, apoptosis, migration and invasion in PC cells. Moreover, we defined whether curcumin exerts its antitumor activity via downregulation of Cdc20 in PC cells. We found that curcumin inhibited the Cdc20 expression, leading to anti-cancer activity in PC cells. These results suggest that curcumin could be useful to inhibit the expression of Cdc20 in PC cells.

\section{Materials and Methods}

\subsection{Cell Culture and Reagents}

Human pancreatic cancer cell lines Patu8988 and Panc-1 were cultured in Dulbecco's Modified Eagle Medium (DMEM) supplemented with 10\% fetal bovine serum and 1\% penicillin and streptomycin. The anti-Cdc20 antibody was purchased from Abcam Company (Cambridge, MA, USA). The anti-p21, anti-B-cell lymphoma 2 (Bcl-2), anti-B-cell lymphoma-extra large (Bcl-xL), anti-Bax, anti-caspase-3 antibodies were obtained from Cell Signaling Technology (Danvers, MA, USA). All secondary antibodies were purchased from Thermo Scientific (Waltham, MA, USA). The anti- $\beta$-actin, anti-Tubulin, and 3-(4,5-dimethyl-2-thiazolyl)-2,5-diphenyl-2-H-tetrazolium bromide (MTT) were purchased from Sigma-Aldrich (St. Louis, MO, USA). Inhibitor of APC/C (Apcin), a Cdc20 inhibitor, was purchased from BostonBiochem (Boston, MA, USA). Lipofectamine 2000 was purchased from Invitrogen (Waltham, MA, USA).

\subsection{MTT Assay}

The transfected PC cells were seeded at $5 \times 10^{3}$ cells/well in 96-well plate for $24 \mathrm{~h}$ and treated with different concentrations of curcumin (chemical abstract service (CAS) number 458-37-7, 99.5\% curcumin). Curcumin was dissolved in dimethyl sulfoxide (DMSO) to make a 30-mM stock solution and was directly added to the medium at different concentrations. Cells were treated with $0.1 \%$ DMSO as the control group. After $48 \mathrm{~h}$ and $72 \mathrm{~h}$, MTT solution $(5 \mathrm{mg} / \mathrm{mL})$ was added to each well and incubated for $4 \mathrm{~h}$ at $37^{\circ} \mathrm{C}$. Then, $100 \mu \mathrm{L}$ DMSO was added to dissolve the MTT-formazan crystals after the supernatant was absorbed. The absorption was measured by the microplate at $490 \mathrm{~nm}$. 


\subsection{Cell Apoptosis Analysis}

The transfected cells were cultured in six-well plate overnight and treated with curcumin for $48 \mathrm{~h}$. Then, cells were harvested and washed with phosphate buffered saline (PBS), resuspended in $500 \mu \mathrm{L}$ binding buffer with $5 \mu \mathrm{L}$ propidium iodide (PI) and $5 \mu \mathrm{L}$ fluorescein isothiocyanate (FITC)-conjugated anti-annexin V antibody. Apoptosis was measured with a FACScalibur flow cytometer (Becton, Dickinson Company, Franklin Lakes, NJ, USA). The Cell Death Detection ELISA Kit was also used for measuring apoptosis in PC cells treated with curcumin and Cdc20 short hairpin RNA (shRNA) according to the manufacturer's protocol. Briefly, the cells were lysed after treatments, and the cell lysates were incubated in microtiter plate modules coated with antihistone antibody, and subsequently incubated with anti-DNA peroxidase followed by color development with 2,2'-azinobis-3-ethylbenzothiazoline-6-sulfonic acid (ABTS) ${ }^{\mathrm{TM}}$ substrate. The optical densities of the samples were determined by using the Ultra Multifunctional Microplate Reader at 405 nanometers (nm).

\subsection{Cell Scratch Assays}

The transfected cells were cultured in 6-well plate. After cells reached almost $100 \%$, the supernatant was absorbed. Yellow pipette tips were used to scratch the cell surface. The cells were washed by PBS and treated with curcumin. The scratched area was photographed with a microscope at $0 \mathrm{~h}$ and $20 \mathrm{~h}$, respectively. The experiment was repeated twice. The quantification of the results represents three times for cell scratch assays.

\subsection{Cell Invasion Assay}

Cell invasion assay was performed to explore the invasive activity of PC cells treated with curcumin or Cdc20 transfection or combination [27]. Briefly, transfected cells were seeded in the upper chamber with serum-free medium and $500 \mu \mathrm{L}$ of complete medium was added in the under chamber with the same concentration of curcumin. After incubation for $24 \mathrm{~h}$, the membrane of the chamber was strained with Giemsa and photographed with a microscope.

\subsection{Transfection}

Cells were seeded into 6-well plates and transfected with Cdc20 cDNA or Cdc20 shRNA or empty vector by lipofectamine 2000 following the instruction's protocol. The transfected cells were subjected to further analysis as described under the results section.

\subsection{Quantitative Real-Time Reverse Transcription-PCR (RT-PCR) Analysis}

The total RNA was extracted with Trizol (Invitrogen, Carlsbad, CA, USA) and reversed-transcribed into cDNA by RevertAid First Strand cDNA Synthesis Kit. PCR were conducted by Power SYBR Green PCR Master Mix. The primers used in the PCR reaction were: Cdc20, forward primer (5'-GACCACTCCTAGCAAACCTGG-3') and reverse primer (5'-GGGCGTCTGGCTGTTTT CA-3'); Glyceraldehyde-3-phosphate dehydrogenase (GAPDH), forward primer (5'-ACCCAGAAG ACTGTGGATGG-3') and reverse primer (5'-CAGTGAGCTTCCCGTTCA G-3').

\subsection{Western Blotting Analysis}

The harvested cells were washed by PBS and treated with protein lysis buffer. The BCA Protein Assay kit (Thermo Scientific, Waltham, MA, USA) was used to measure the concentrations of the proteins. Protein samples were separated by electrophoresis in sodium dodecyl sulfate (SDS)-polyacrylamide gel and then transferred onto a polyvinylidene difluoride (PVDF) membrane, and then incubated with primary antibody at $4{ }^{\circ} \mathrm{C}$ overnight. Then, cells were washed with Tris-buffered saline and Tween 20 (TBST) for three times and incubated with second antibody at 
room temperature for $1 \mathrm{~h}$. Then the expression of protein was determined by enhanced luminal-based chemiluminescent (ECL) assay.

\subsection{Statistical Analysis}

All statistical analyses were measured by GraphPad Prism 5.0 (Graph Pad Software, La Jolla, San Diego, CA, USA). ANOVA assay was used to evaluate statistical significance. Results were presented as means \pm SD. $p<0.05$ was considered as statistically significant.

\section{Results}

\subsection{Curcumin Inhibited the Expression of $C d c 20$}

Multiple studies have shown that curcumin inhibited cell growth in PC cells. Since Cdc20 has been considered to play an important oncogenic role in pancreatic tumorigenesis, we tested whether curcumin could suppress the expression of Cdc20 in PC cells. Real-time (RT)-PCR) was performed to measure the mRNA level of Cdc20 in PC cells treated with curcumin. Our RT-PCR results showed that curcumin treatment significantly decreased Cdc20 mRNA level in both Patu8988 and Panc-1 cells (Figure 1A). To determine whether curcumin could decrease the Cdc20 protein level, western blotting analysis was conducted to measure the Cdc20 protein expression in PC cells after curcumin treatment. We found that curcumin remarkably reduced the Cdc20 protein level in PC cells (Figure 1B,C). It is known that Bim and p21 are two downstream targets of Cdc20. Indeed, we observed that curcumin treatment led to upregulation of Bim and p21 in both PC cells (Figure 1B,C). These findings revealed that curcumin inhibited Cdc20 expression in PC cells.

\subsection{Overexpression of Cdc20 Decreased Curcumin-Induced Cell Growth Inhibition}

To explore whether curcumin-mediated cell growth inhibition is through suppression of Cdc20 in PC cells, Patu8988 and Panc-1 cells were transfected with Cdc20 cDNA or empty vector as control group. Our MTT results showed that overexpression of Cdc20 significantly enhanced cell growth in both PC cell lines (Figure 2A). Consistently, curcumin inhibited cell growth in Patu8988 and Panc-1 cells (Figure 2A). Importantly, overexpression of Cdc20 rescued cell growth suppression by curcumin treatment in PC cells (Figure 2A). Our data suggest that curcumin exerts its inhibition of cell growth via downregulation of Cdc20 in PC cells.

A

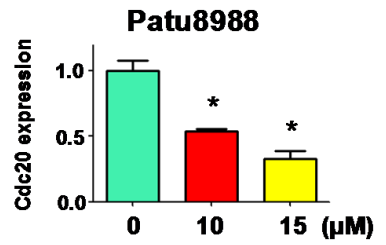

B

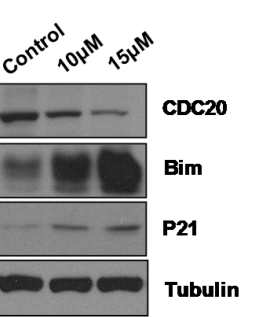

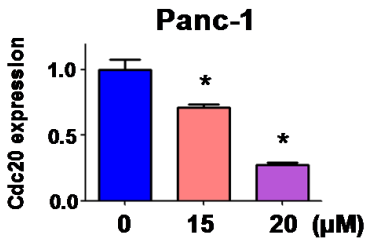

Panc-1

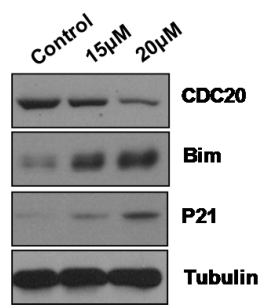

Figure 1. Cont. 
C
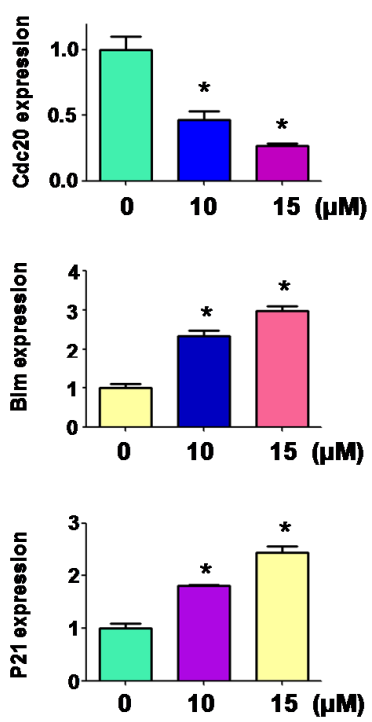
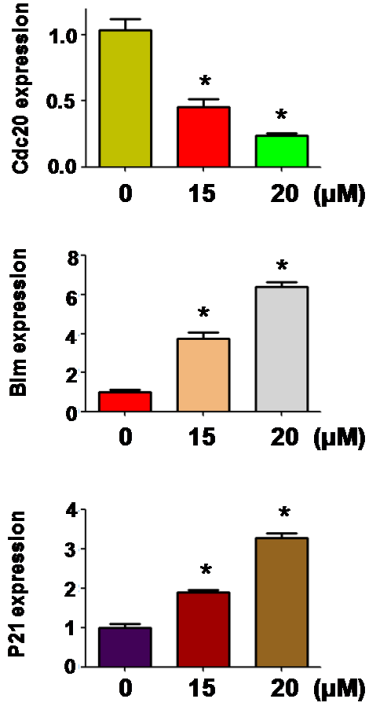

Figure 1. Curcumin decreased cell division cycle 20 (Cdc20) expression at RNA and protein levels. (A) The Cdc20 mRNA expression was measured by real-time reverse transcription-PCR (RT-PCR) in PC cells treated with curcumin. ${ }^{*} p<0.05$, vs. control; (B) The expression of Cdc20, Bim, and p21 was detected using Western blotting analysis in pancreatic cancer (PC) cells after curcumin treatment; (C) Quantitative results are illustrated for panel B. ${ }^{*} p<0.05$, compared to the control.

Patu8988

A

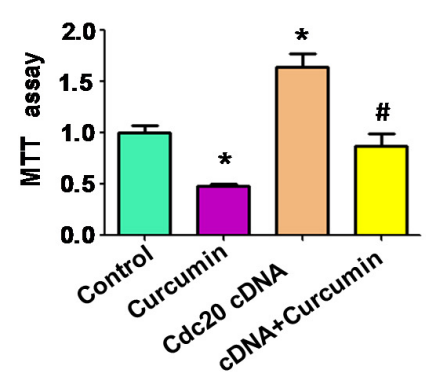

B
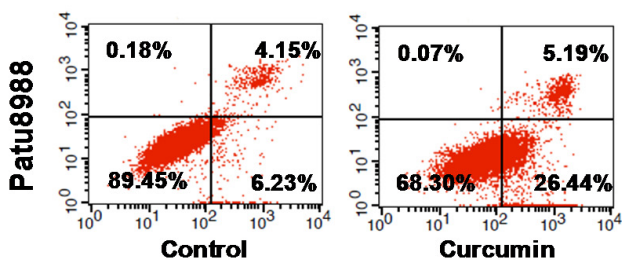

Curcumin
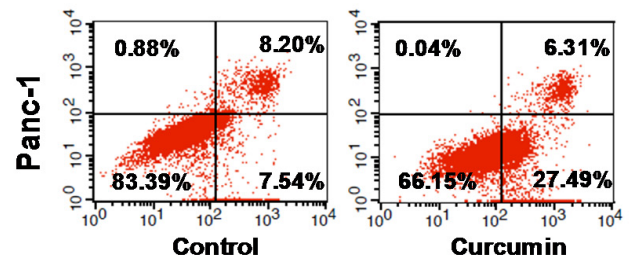

Panc-1

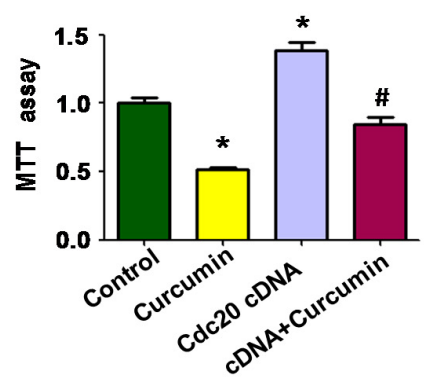

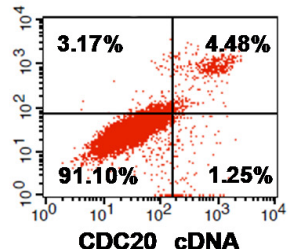

CDC20 cDNA

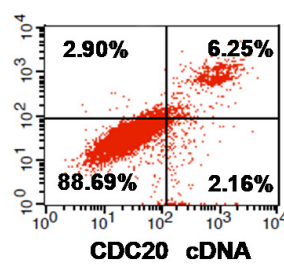

Figure 2. Cont. 
C

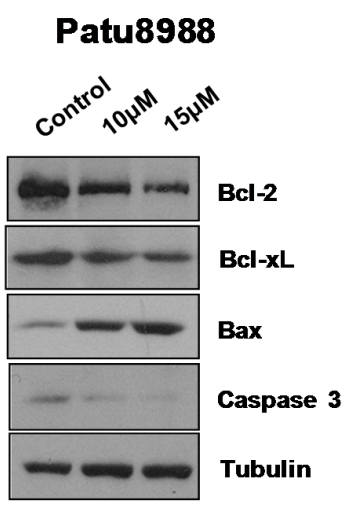

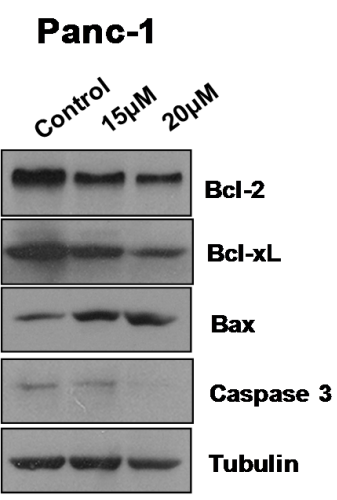

Figure 2. Overexpression of Cdc20 decreased curcumin-induced cell growth inhibition and apoptosis. (A) A 3-(4,5-dimethyl-2-thiazolyl)-2,5-diphenyl-2-H-tetrazolium bromide (MTT) assay was performed to measure the cell growth in PC cells with Cdc20 cDNA transfection in combination with curcumin treatment. ${ }^{*} p<0.05$, compared with control; ${ }^{\#} p<0.05$ compared with curcumin treatment or Cdc20 cDNA transfection alone; (B) Cell apoptosis was determined by flow cytometry in PC cells treated with curcumin plus Cdc20 cDNA transfection; (C) Western blotting analysis was performed to measure the expression of Bcl-2 family and caspase- 3 in PC cells after curcumin treatment.

\subsection{Overexpression of $C d c 20$ Abrogated Curcumin-Triggered Cell Apoptosis}

It is known that curcumin treatment leads to induction of cell apoptosis in PC cells. In line with this concept, we found that curcumin induced cell apoptosis in both PC cell lines (Figure 2B). Moreover, we found that curcumin enhanced apoptosis via inhibition of Bcl-2, Bcl-xL and upregulation of Bax and Caspase-3 in PC cell lines (Figure 2C). One study has revealed that Cdc20 inhibited cell apoptosis via degradation of Bim in human cancer cells [28]. Indeed, we found that overexpression of Cdc20 suppressed cell apoptosis in PC cells (Figure 2B). Strikingly, Cdc20 cDNA transfection abrogated curcumin-induced cell apoptosis in PC cells (Figure 2B). Therefore, curcumin-triggered cell apoptosis is partly through downregulation of Cdc20 in PC cells.

\subsection{Overexpression of Cdc20 Retarded Curcumin-Mediated Cell Motility Inhibition}

Next, to investigate whether Cdc20 could govern cell motility in PC cells, the Transwell chambers assay was used to measure the cell invasion in PC cells treated with curcumin and Cdc20 cDNA transfection. The results from Transwell assays showed that curcumin significantly reduced the cell invasion in PC cells (Figure 3A). Overexpression of Cdc20 promoted cell invasion in both PC cells (Figure 3A). Notably, overexpression of Cdc20 retarded curcumin-mediated cell invasion inhibition (Figure 3A). To further validate the function of curcumin in cell motility, the wound healing assay was performed in PC cells with Cdc20 cDNA transfection and curcumin treatment. We observed that curcumin remarkably inhibited cell migration in PC cells (Figure 3B). Overexpression of Cdc20 promoted cell migration in PC cells (Figure 3B). Importantly, overexpression of Cdc20 blocked curcumin-induced cell migration inhibition (Figure 3B). These findings suggest that curcumin inhibited cell motility via down-regulation of Cdc20 in PC cells.

\subsection{Overexpression of $C d c 20$ Abrogated Activation of 21 and Bim by Curcumin}

It has been well documented that Cdc20 controlled the ubiquitin-mediated degradation of p21, leading to regulation of cell growth [29]. Therefore, we investigated whether overexpression of Cdc20 by its cDNA could block the upregulation of 21 by curcumin treatment. In keeping with this, we found that overexpression of Cdc20 abrogated expression of p21 by curcumin in PC cells (Figure 4A,B). One study demonstrated that Bim is one key target of Cdc20, which is involved in regulation of cell apoptosis [28]. Mechanistically, we found that upregulation of Cdc20 abrogated activation of 
Bim induced by curcumin in PC cells (Figure 4A,B). These results provide the molecular insight that curcumin exhibits anti-tumor activity through downregulation of Cdc20 and its downstream targets including p21 and Bim.

A
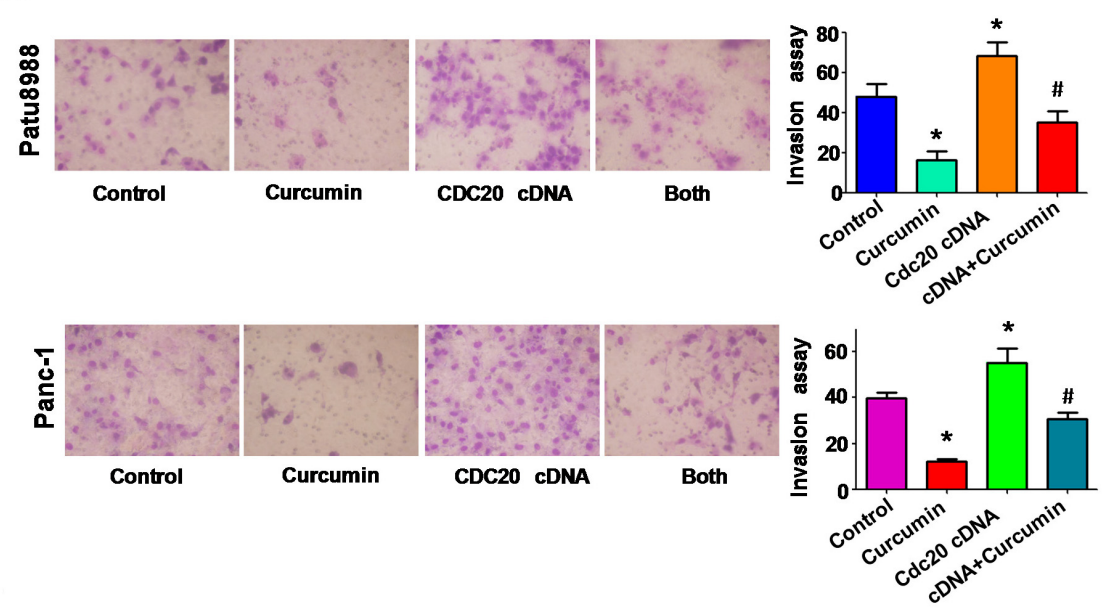

B
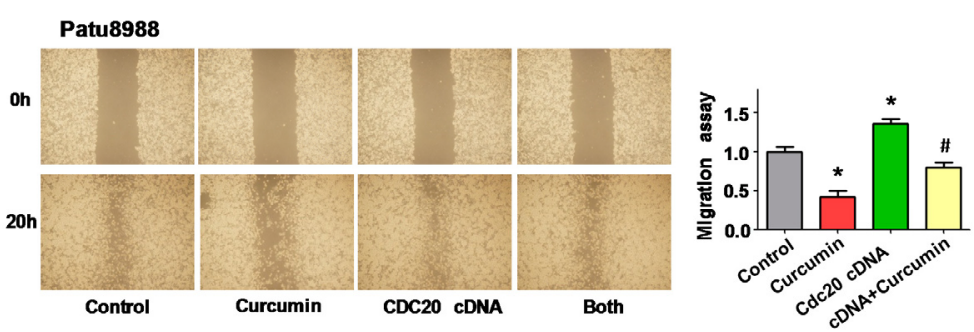

Panc-1
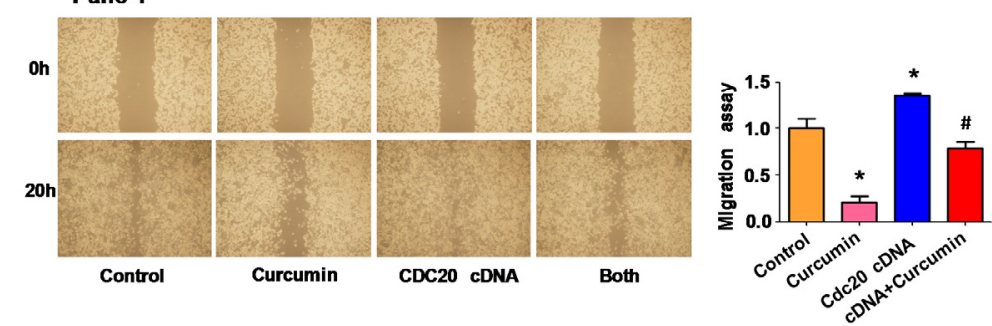

Figure 3. Overexpression of Cdc20 retarded curcumin-mediated cell motility inhibition. (A) Left panel, invasion assay was conducted in PC cells after Cdc20 cDNA transfection and curcumin treatment. Right panel, quantitative results are illustrated for left panel. ${ }^{*} p<0.05$, compared with control; \# $p<0.05$ compared with curcumin treatment or Cdc20 cDNA transfection alone; (B) Left panel, the wound healing assay was performed to measure the cell migration in PC cells after Cdc20 cDNA transfection and curcumin treatment. Both: Cdc20 CDNA + curcumin. Right panel, quantitative results are illustrated for left panel. ${ }^{*} p<0.05$, compared with control; ${ }^{*} p<0.05$ compared with curcumin treatment or Cdc20 cDNA transfection alone. 
A
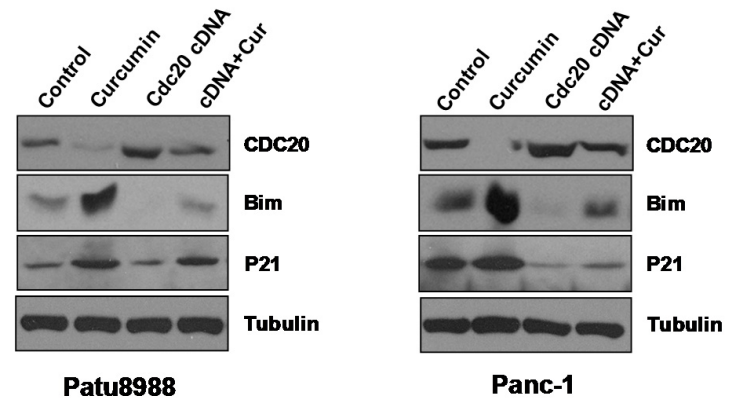

$\mathbf{B}$
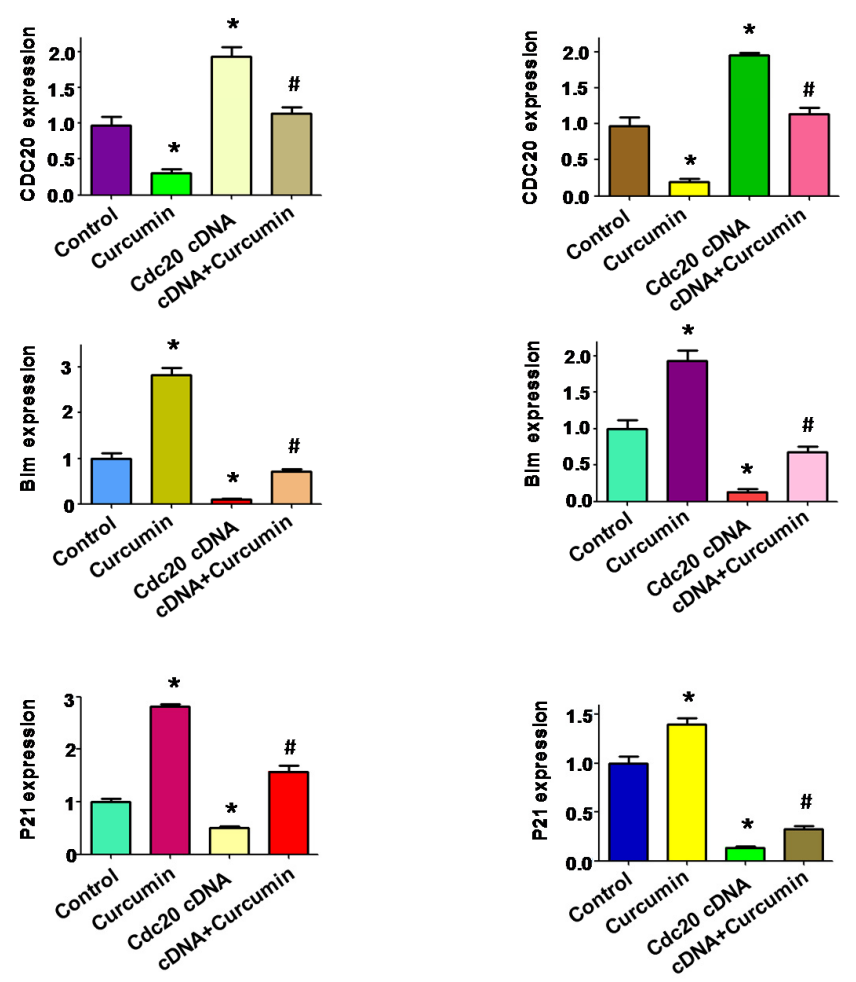

Figure 4. The expression of Cdc20, Bim and p21 was measured in PC cells. (A) The expression of Cdc20 and its targets Bim and p21 was measured by western blotting in PC cells with Cdc20 cDNA transfection and curcumin treatment (15 $\mu \mathrm{M}$ curcumin for patu8988 and $20 \mu \mathrm{M}$ curcumin for Panc-1); (B) Right panel: Quantitative results are illustrated for left panel. ${ }^{*} p<0.05$, compared with control; \# $p<0.05$ compared with curcumin treatment or Cdc20 cDNA transfection.

\subsection{Downregulation of Cdc20 Promotes Curcumin-Mediated Cell Growth Inhibition and Apoptosis}

To more deeply determine whether curcumin mediated cell growth suppression via downregulation of Cdc20, MTT assay was conducted in PC cells treated with Cdc20 shRNA and curcumin. Consistent with the oncogenic role of $\mathrm{Cdc} 20$, we found that downregulation of $\mathrm{Cdc} 20$ caused cell growth inhibition (Figure 5A). Moreover, our results showed that downregulation of Cdc20 expression significantly suppressed cell growth induced by curcumin (Figure 5A). Furthermore, downregulation of Cdc20 by its shRNA induced cell apoptosis in PC cells (Figure 5B). Accordingly, Cdc20 shRNA transfected cells were significantly more sensitive to curcumin-induced apoptosis in PC cells (Figure 5B). To further validate our results, apcin as a Cdc20 inhibitor was used to determine whether inhibition of Cdc20 by its inhibitor promoted cell apoptosis in PC cells. We observed that $50 \mu \mathrm{M}$ of apcin induced apoptosis in both PC cells (Figure 5C). The results from ELISA for histone/DNA fragment analysis also confirmed that inhibition of Cdc20 enhanced curcumin-triggered cell apoptosis (Supplementary Materials Figure S1). 
A

Patu8988

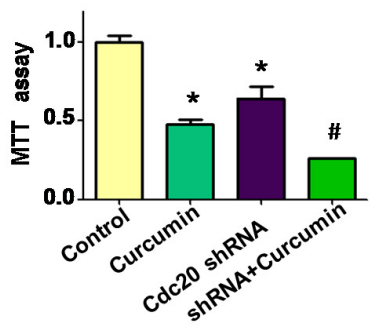

B
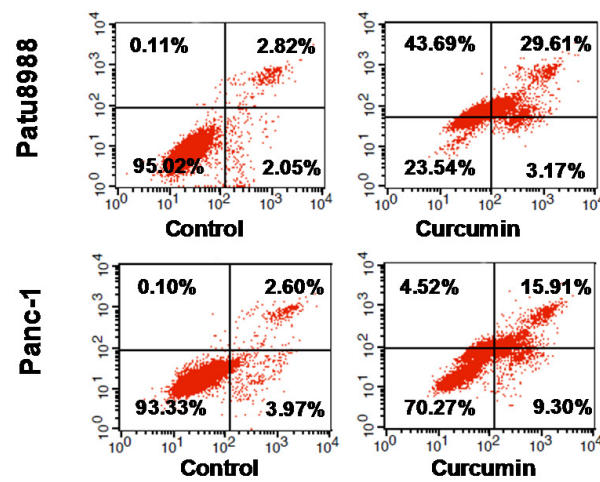

Curcumin

C
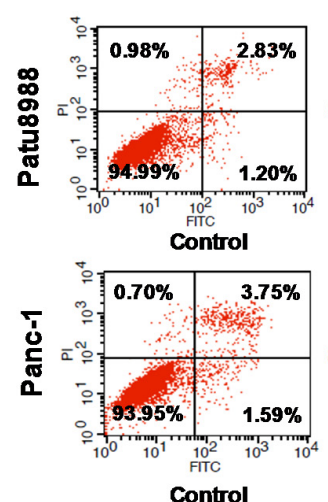

Panc-1

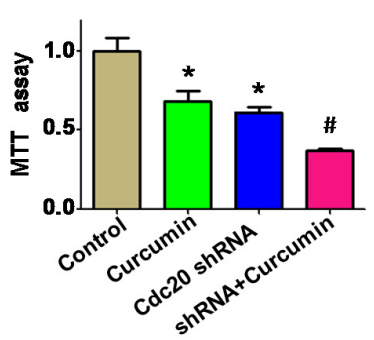

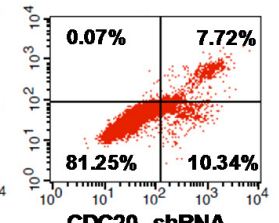

CDC20 ShRNA

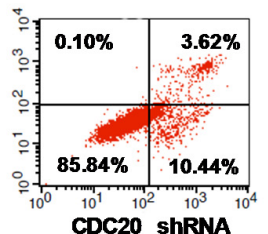

CDC20 ShRNA
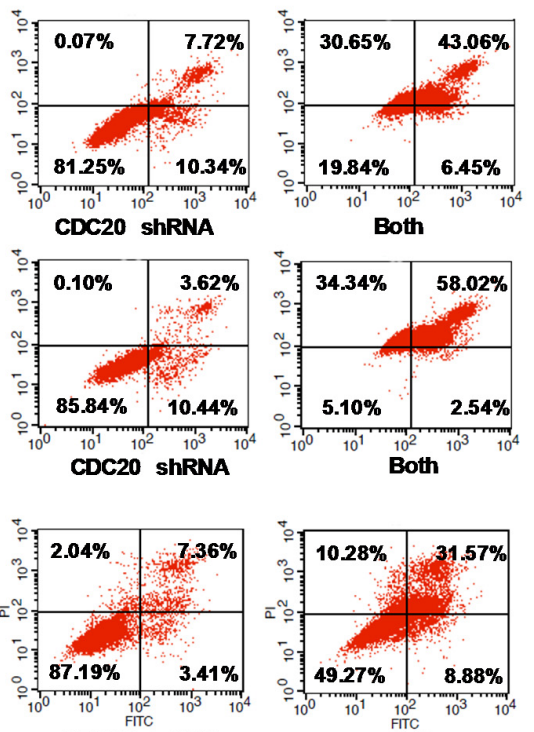

CDC20 inhibitor

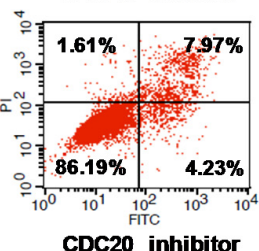

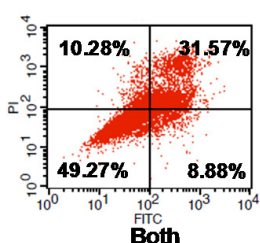

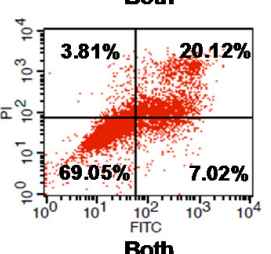

Figure 5. The effect of Cdc20 downregulation on cell growth and apoptosis. (A) MTT assay was conducted to determine the effect of Cdc20 shRNA in combination with curcumin treatment on PC cell growth. ${ }^{*} p<0.05$, compared with control; ${ }^{*} p<0.05$ compared with curcumin treatment or Cdc20 shRNA transfection; (B) Apoptosis was detected by flow cytometry in PC cells with Cdc20 shRNA transfection and curcumin treatment. Both: curcumin + Cdc20 shRNA. C. Apoptosis was analyzed by flow cytometry in PC cells with Cdc20 inhibitor (50 $\mu \mathrm{M}$ Apcin) and curcumin treatment. Both: curcumin + Cdc20 inhibitor. PI: propidium iodide; FITC: fluorescein isothiocyanate.

\subsection{Downregulation of $C d c 20$ by shRNA Promotes Curcumin-Induced Cell Invasion Inhibition}

To further validate whether curcumin exhibited its anti-tumor invasion via down-regulation of Cdc20, Tanswell chamber assays and wound healing assays were conducted in PC cells treated with curcumin and Cdc20 shRNA transfection. We found that downregulation of Cdc20 retarded cell invasion in both PC cell lines (Figure 6A). Concurrently, downregulation of Cdc20 in combination of curcumin treatment led to inhibition of cell invasion to a greater degree compared with curcumin treatment alone or shRNA transfection alone (Figure 6A). Consistently, the wound healing assay showed similar results, suggesting that downregulation of Cdc20 promoted curcumin-mediated cell migration inhibition (Figure 6B). Intriguingly, our results revealed that Cdc20 shRNA increased the expression of Bim and p21 expression (Figure 7A,B). Importantly, curcumin plus Cdc20 shRNA 
increased p21 and Bim expression to greater degree compared to curcumin alone or shRNA transfection alone (Figure 7A,B).

$\mathbf{A}$

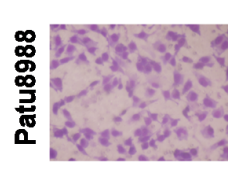

Control

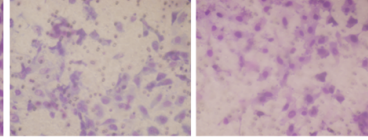

Curcumin

CDC20 ShRNA

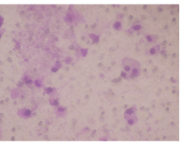

Both
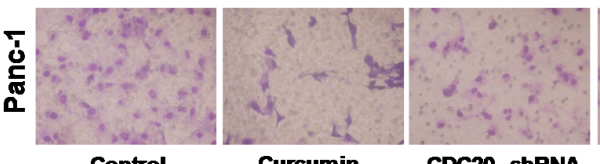

Curcumin

CDC20 ShRNA

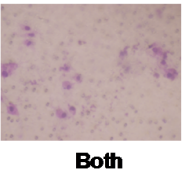

Both
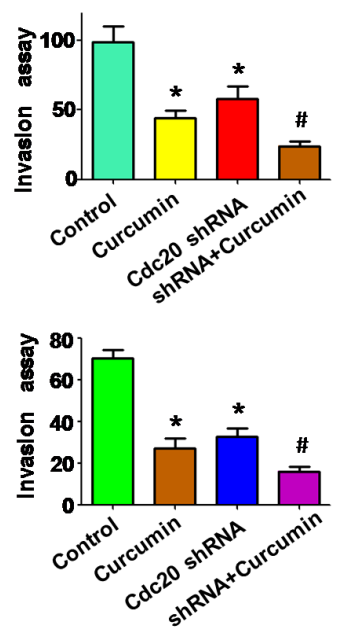

B Patu8988
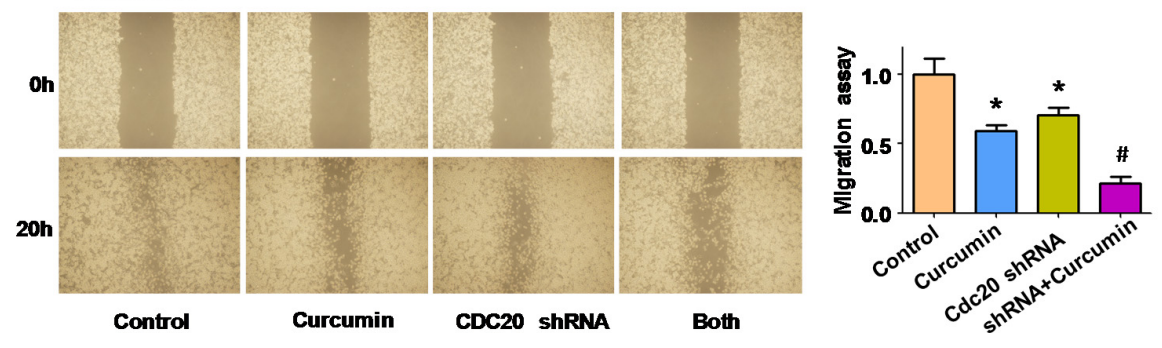

Panc-1
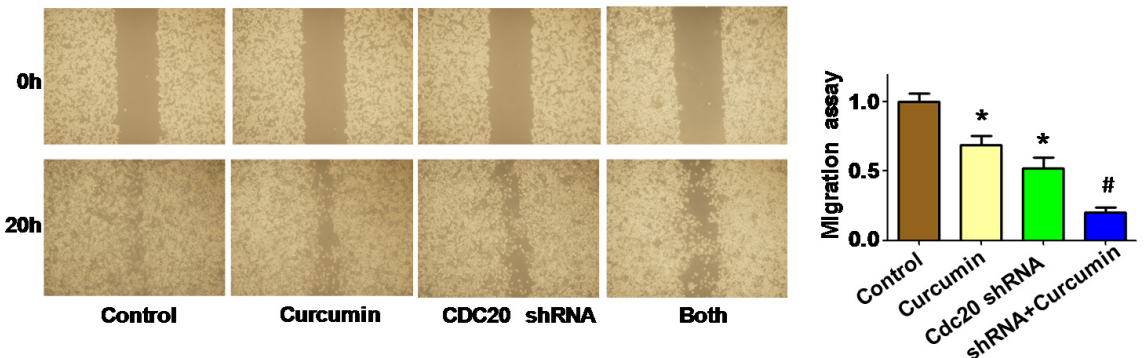

Figure 6. The effect of Cdc20 downregulation on cell migration, and invasion. (A) Invasion assay was conducted in PC cells after Cdc20 shRNA transfection and curcumin treatment; (B) The wound healing assay was used to measure the cell migration in PC cells after Cdc20 shRNA transfection and curcumin treatment. Both: curcumin + Cdc20 shRNA. ${ }^{*} p<0.05$, vs. control; ${ }^{\#} p<0.05$ vs. curcumin treatment or Cdc20 shRNA transfection. 
A
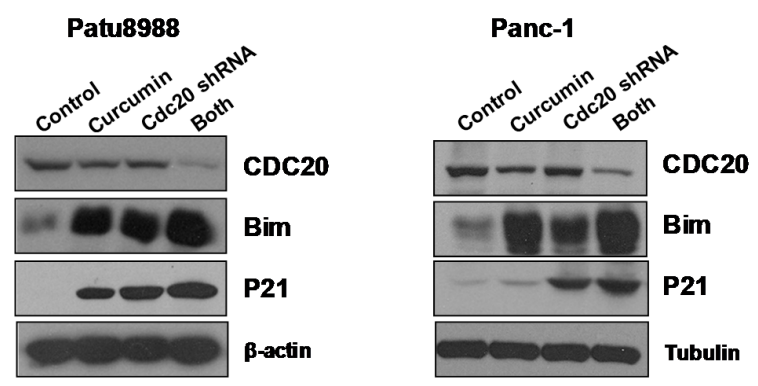

B
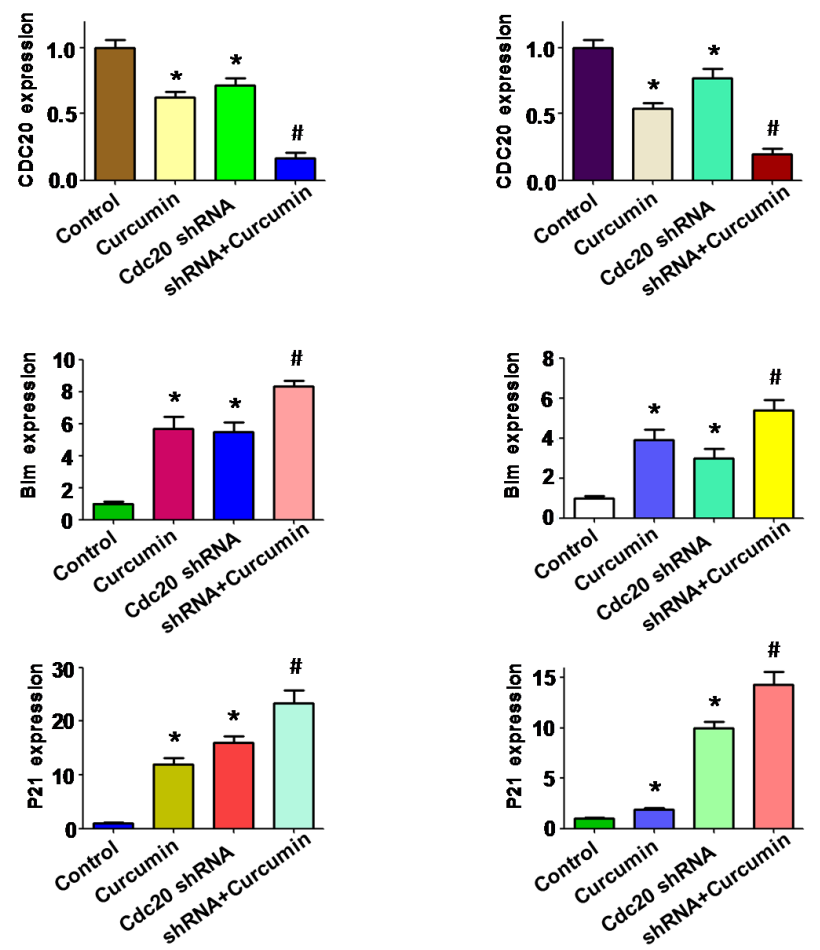

Figure 7. The expression of Cdc20, Bim and p21 was measured in PC cells. (A) The expression of Cdc20 and its targets Bim and p21 was measured by Western blotting in PC cells after Cdc20 shRNA transfection and curcumin treatment; (B) Quantitative results are illustrated for panel A. * $p<0.05$, compared with control; ${ }^{\#} p<0.05$ compared with curcumin treatment or Cdc20 shRNA transfection.

\section{Discussion}

Studies have defined the molecular mechanism of curcumin-induced tumor suppression. For example, curcumin induced cell death through reduction of the inhibitors of apoptosis in PC cells [30]. Moreover, curcumin induced cell apoptosis via inhibition of forkhead box $\mathrm{O} 1$ and PI3K/Akt pathway [31]. Our previous study showed that curcumin exerted its anti-tumor activity via down-regulation of Yes-associated protein and transcriptional co-activator with PDZ binding motif (YAP/TAZ) expression in PC cells [32]. Moreover, it has been reported that curcumin inhibited cell growth and invasion via suppression of Skp2 [33]. Cao et al. validated that curcumin inhibited $\mathrm{H}_{2} \mathrm{O}_{2}$-induced invasion and migration through inactivation of ERK/NF- $\mathrm{B}$ pathway in PC [34]. Furthermore, curcumin was found to inhibit hypoxia-induced epithelial-mesenchymal transition (EMT) in PC cells via inhibition of the hedgehog signaling pathway [35]. In our current study, we found that curcumin suppressed cell growth and triggered cell cycle arrest and induced apoptosis in PC cells. We further demonstrated that curcumin retarded cell migration and invasion in PC 
cells. Mechanistically, curcumin exerts its anti-tumor functions through down-regulation of Cdc20 expression in PC cells. These results indicated that curcumin could be an effective agent for the treatment of PC. Targeting numerous of molecules by curcumin could represent a novel approach for treating PC patients.

Robust evidence has demonstrated that $\mathrm{Cdc} 20$ plays an oncogenic role in human tumorigenesis. Mechanistically, overexpression of Cdc20 caused impairment of the spindle assembly checkpoint and aneuploidization in oral cancer [36]. Another study revealed that Cdc20 suppressed apoptosis through targeting Bim for ubiquitination and destruction [28]. Additionally, Cdc20 induced degradation of conductin-regulated Wnt/ $\beta$-catenin signaling for maximal activity during G1/S [37]. Furthermore, Cdc20 could be negatively governed by p53 [38]. Notably, depletion of Cdc20 by its shRNA inhibited the cell growth and induced cell cycle arrest [39]. In line with this report, our study showed that overexpression of Cdc20 enhanced cell growth, whereas depletion of Cdc20 inhibited cell growth in PC cells. Moreover, depletion of Cdc20 led to enhancement of the cytotoxicity of paclitaxel and increased the effect of irradiation against PC cells [39]. Similarly, silencing the expression of Cdc20 by liposomally-encapsulated Cdc20 siRNA inhibited tumor growth via induction of apoptosis of the tumor endothelial cells [40].

It is important to discover the inhibitors of Cdc20 for the treatment of human cancers. Tosyl-L-arginine methyl ester (TAME) reduced Cdc20 association with the APC, leading to inhibition of APC E3 ligase activity [41]. Strikingly, pro-TAME with cell permeable activity disrupted the APC-Cdc20/Cdh1 interaction to inhibit APC activation [41]. Furthermore, APC inhibitors (apsin) could bind $\mathrm{Cdc} 20$ and block substrate recognition and inhibit the ubiquitination of Cdc20 substrates [42]. Jiang et al. found that ganodermanontriol exerts its inhibitory effects of cell growth and invasiveness via the downregulation of $\mathrm{Cdc} 20$ in breast cancer cells [43]. One study showed that withaferin A modulated the spindle assembly checkpoint by degradation of Mad2-Cdc20 complex in colorectal cancer cells [44]. Zhang et al. identified that compound 331 selectively induced glioma cell death through downregulation of Cdc20 [45]. Recently, rottlerin was found to downregulate the expression of Cdc20 in glioma cells [46]. Our current study showed that curcumin inhibited the expression of Cdc20.

\section{Conclusions}

In the current study, our results demonstrated that curcumin suppressed Cdc20 expression in PC cells, suggesting that curcumin could be a promising agent for treating human PC cancer. However, further investigation in the future is required to explore whether curcumin sensitizes chemotherapeutic drugs via downregulation of Cdc20 in PC patients.

Supplementary Materials: The following are available online at http:/ /www.mdpi.com/2072-6643/9/2/109/s1, Figure S1: Cell apoptosis was measured with the histone/DNA fragment analysis by using an enzyme-linked immune adsorbent assay.

Acknowledgments: We thank the colleagues for their excellent suggestions to improve this manuscript.

Author Contributions: Z.-w.W. and S.-s.T. conceived and designed the experiments; Y.Z. and Y.-b.X. performed the experiments; Y.Z. and H.L. analyzed the data; Y.Z. and D.Q. contributed reagents/materials/analysis tools; Y.Z. and S.-s.T. wrote the paper.

Conflicts of Interest: The authors declare no conflict of interest.

\section{References}

1. Siegel, R.L.; Miller, K.D.; Jemal, A. Cancer statistics, 2016. CA Cancer J. Clin. 2016, 66, 7-30. [CrossRef] [PubMed]

2. Zanotto-Filho, A.; Braganhol, E.; Edelweiss, M.I.; Behr, G.A.; Zanin, R.; Schroder, R.; Simoes-Pires, A.; Battastini, A.M.; Moreira, J.C. The curry spice curcumin selectively inhibits cancer cells growth in vitro and in preclinical model of glioblastoma. J. Nutr. Biochem. 2012, 23, 591-601. [CrossRef] [PubMed] 
3. Weissenberger, J.; Priester, M.; Bernreuther, C.; Rakel, S.; Glatzel, M.; Seifert, V.; Kogel, D. Dietary curcumin attenuates glioma growth in a syngeneic mouse model by inhibition of the JAK1,2/STAT3 signaling pathway. Clin. Cancer Res. 2010, 16, 5781-5795. [CrossRef] [PubMed]

4. Bangaru, M.L.; Chen, S.; Woodliff, J.; Kansra, S. Curcumin (diferuloylmethane) induces apoptosis and blocks migration of human medulloblastoma cells. Anticancer Res. 2010, 30, 499-504. [PubMed]

5. Masuelli, L.; Di Stefano, E.; Fantini, M.; Mattera, R.; Benvenuto, M.; Marzocchella, L.; Sacchetti, P.; Focaccetti, C.; Bernardini, R.; Tresoldi, I.; et al. Resveratrol potentiates the in vitro and in vivo anti-tumoral effects of curcumin in head and neck carcinomas. Oncotarget 2014, 5, 10745-10762. [CrossRef] [PubMed]

6. Hidaka, H.; Ishiko, T.; Furuhashi, T.; Kamohara, H.; Suzuki, S.; Miyazaki, M.; Ikeda, O.; Mita, S.; Setoguchi, T.; Ogawa, M. Curcumin inhibits interleukin 8 production and enhances interleukin 8 receptor expression on the cell surface: Impact on human pancreatic carcinoma cell growth by autocrine regulation. Cancer 2002, 95 , 1206-1214. [CrossRef] [PubMed]

7. Li, L.; Aggarwal, B.B.; Shishodia, S.; Abbruzzese, J.; Kurzrock, R. Nuclear factor-kappaB and IkappaB kinase are constitutively active in human pancreatic cells, and their down-regulation by curcumin (diferuloylmethane) is associated with the suppression of proliferation and the induction of apoptosis. Cancer 2004, 101, 2351-2362. [CrossRef] [PubMed]

8. Jutooru, I.; Chadalapaka, G.; Lei, P.; Safe, S. Inhibition of NFkappaB and pancreatic cancer cell and tumor growth by curcumin is dependent on specificity protein down-regulation. J. Biol. Chem. 2010, 285, 25332-25344. [CrossRef] [PubMed]

9. Lev-Ari, S.; Zinger, H.; Kazanov, D.; Yona, D.; Ben-Yosef, R.; Starr, A.; Figer, A.; Arber, N. Curcumin synergistically potentiates the growth inhibitory and pro-apoptotic effects of celecoxib in pancreatic adenocarcinoma cells. Biomed. Pharmacother. 2005, 59 (Suppl. 2), S276-S280. [CrossRef]

10. Kunnumakkara, A.B.; Guha, S.; Krishnan, S.; Diagaradjane, P.; Gelovani, J.; Aggarwal, B.B. Curcumin potentiates antitumor activity of gemcitabine in an orthotopic model of pancreatic cancer through suppression of proliferation, angiogenesis, and inhibition of nuclear factor-kappaB-regulated gene products. Cancer Res. 2007, 67, 3853-3861. [CrossRef] [PubMed]

11. Lev-Ari, S.; Starr, A.; Vexler, A.; Karaush, V.; Loew, V.; Greif, J.; Fenig, E.; Aderka, D.; Ben-Yosef, R. Inhibition of pancreatic and lung adenocarcinoma cell survival by curcumin is associated with increased apoptosis, down-regulation of COX-2 and EGFR and inhibition of Erk1/2 activity. Anticancer Res. 2006, 26, 4423-4430. [PubMed]

12. Sahu, R.P.; Batra, S.; Srivastava, S.K. Activation of ATM/Chk1 by curcumin causes cell cycle arrest and apoptosis in human pancreatic cancer cells. Br. J. Cancer 2009, 100, 1425-1433. [CrossRef] [PubMed]

13. Glienke, W.; Maute, L.; Wicht, J.; Bergmann, L. Wilms' tumour gene 1 (WT1) as a target in curcumin treatment of pancreatic cancer cells. Eur. J. Cancer 2009, 45, 874-880. [CrossRef] [PubMed]

14. Glienke, W.; Maute, L.; Wicht, J.; Bergmann, L. Curcumin inhibits constitutive STAT3 phosphorylation in human pancreatic cancer cell lines and downregulation of survivin/BIRC5 gene expression. Cancer Investig. 2010, 28, 166-171. [CrossRef] [PubMed]

15. Sun, X.D.; Liu, X.E.; Huang, D.S. Curcumin reverses the epithelial-mesenchymal transition of pancreatic cancer cells by inhibiting the hedgehog signaling pathway. Oncol. Rep. 2013, 29, 2401-2407. [PubMed]

16. Wang, L.; Zhang, J.; Wan, L.; Zhou, X.; Wang, Z.; Wei, W. Targeting Cdc20 as a novel cancer therapeutic strategy. Pharmacol. Ther. 2015, 151, 141-151. [CrossRef] [PubMed]

17. Kim, Y.; Choi, J.W.; Lee, J.H.; Kim, Y.S. Mad2 and Cdc20 are upregulated in high-grade squamous intraepithelial lesions and squamous cell carcinomas of the uterine cervix. Int. J. Gynecol. Pathol. 2014, 33, 517-523. [CrossRef] [PubMed]

18. Moura, I.M.; Delgado, M.L.; Silva, P.M.; Lopes, C.A.; do Amaral, J.B.; Monteiro, L.S.; Bousbaa, H. High Cdc20 expression is associated with poor prognosis in oral squamous cell carcinoma. J. Oral Pathol. Med. 2014, 43, 225-231. [CrossRef] [PubMed]

19. Wu, W.J.; Hu, K.S.; Wang, D.S.; Zeng, Z.L.; Zhang, D.S.; Chen, D.L.; Bai, L.; Xu, R.H. Cdc20 overexpression predicts a poor prognosis for patients with colorectal cancer. J. Transl. Med. 2013, 11, 142. [CrossRef] [PubMed]

20. Marucci, G.; Morandi, L.; Magrini, E.; Farnedi, A.; Franceschi, E.; Miglio, R.; Calo, D.; Pession, A.; Foschini, M.P.; Eusebi, V. Gene expression profiling in glioblastoma and immunohistochemical evaluation of IGFBP-2 and Cdc20. Virchows Arch. 2008, 453, 599-609. [CrossRef] [PubMed] 
21. Li, J.; Gao, J.Z.; Du, J.L.; Huang, Z.X.; Wei, L.X. Increased Cdc20 expression is associated with development and progression of hepatocellular carcinoma. Int. J. Oncol. 2014, 45, 1547-1555. [CrossRef] [PubMed]

22. Karra, H.; Repo, H.; Ahonen, I.; Loyttyniemi, E.; Pitkanen, R.; Lintunen, M.; Kuopio, T.; Soderstrom, M.; Kronqvist, P. Cdc20 and securin overexpression predict short-term breast cancer survival. Br. J. Cancer 2014, 110, 2905-2913. [CrossRef] [PubMed]

23. Ding, Z.Y.; Wu, H.R.; Zhang, J.M.; Huang, G.R.; Ji, D.D. Expression characteristics of Cdc20 in gastric cancer and its correlation with poor prognosis. Int. J. Clin. Exp. Pathol. 2014, 7, 722-727. [PubMed]

24. Choi, J.W.; Kim, Y.; Lee, J.H.; Kim, Y.S. High expression of spindle assembly checkpoint proteins Cdc20 and Mad2 is associated with poor prognosis in urothelial bladder cancer. Virchows Arch. 2013, 463, 681-687. [CrossRef] [PubMed]

25. Kato, T.; Daigo, Y.; Aragaki, M.; Ishikawa, K.; Sato, M.; Kaji, M. Overexpression of Cdc20 predicts poor prognosis in primary non-small cell lung cancer patients. J. Surg. Oncol. 2012, 106, 423-430. [CrossRef] [PubMed]

26. Chang, D.Z.; Ma, Y.; Ji, B.; Liu, Y.; Hwu, P.; Abbruzzese, J.L.; Logsdon, C.; Wang, H. Increased Cdc20 expression is associated with pancreatic ductal adenocarcinoma differentiation and progression. J. Hematol. Oncol. 2012, 5, 15. [CrossRef] [PubMed]

27. Yang, Q.; Wang, Y.; Lu, X.; Zhao, Z.; Zhu, L.; Chen, S.; Wu, Q.; Chen, C.; Wang, Z. MiR-125b regulates epithelial-mesenchymal transition via targeting Sema4C in paclitaxel-resistant breast cancer cells. Oncotarget 2015, 6, 3268-3279. [CrossRef] [PubMed]

28. Wan, L.; Tan, M.; Yang, J.; Inuzuka, H.; Dai, X.; Wu, T.; Liu, J.; Shaik, S.; Chen, G.; Deng, J.; et al. Apc(Cdc20) suppresses apoptosis through targeting bim for ubiquitination and destruction. Dev. Cell 2014, 29, 377-391. [CrossRef] [PubMed]

29. Amador, V.; Ge, S.; Santamaria, P.G.; Guardavaccaro, D.; Pagano, M. APC/C(Cdc20) controls the ubiquitin-mediated degradation of p21 in prometaphase. Mol. Cell 2007, 27, 462-473. [CrossRef] [PubMed]

30. Diaz Osterman, C.J.; Gonda, A.; Stiff, T.; Sigaran, U.; Valenzuela, M.M.; Ferguson Bennit, H.R.; Moyron, R.B.; Khan, S.; Wall, N.R. Curcumin induces pancreatic adenocarcinoma cell death via reduction of the inhibitors of apoptosis. Pancreas 2016, 45, 101-109. [CrossRef] [PubMed]

31. Zhao, Z.; Li, C.; Xi, H.; Gao, Y.; Xu, D. Curcumin induces apoptosis in pancreatic cancer cells through the induction of forkhead box O1 and inhibition of the PI3K/Akt pathway. Mol. Med. Rep. 2015, 12, 5415-5422. [PubMed]

32. Zhou, X.; Su, J.; Feng, S.; Wang, L.; Yin, X.; Yan, J.; Wang, Z. Antitumor activity of curcumin is involved in down-regulation of YAP/TAZ expression in pancreatic cancer cells. Oncotarget 2016. [CrossRef] [PubMed]

33. Su, J.; Zhou, X.; Wang, L.; Yin, X.; Wang, Z. Curcumin inhibits cell growth and invasion and induces apoptosis through down-regulation of Skp2 in pancreatic cancer cells. Am. J. Cancer Res. 2016, 6, 1949-1962. [PubMed]

34. Cao, L.; Liu, J.; Zhang, L.; Xiao, X.; Li, W. Curcumin inhibits $\mathrm{H}_{2} \mathrm{O}_{2}$-induced invasion and migration of human pancreatic cancer via suppression of the ERK/NF-kappaB pathway. Oncol. Rep. 2016, 36, 2245-2251. [PubMed]

35. Cao, L.; Xiao, X.; Lei, J.; Duan, W.; Ma, Q.; Li, W. Curcumin inhibits hypoxia-induced epithelialmesenchymal transition in pancreatic cancer cells via suppression of the hedgehog signaling pathway. Oncol. Rep. 2016, 35, 3728-3734. [PubMed]

36. Mondal, G.; Sengupta, S.; Panda, C.K.; Gollin, S.M.; Saunders, W.S.; Roychoudhury, S. Overexpression of Cdc20 leads to impairment of the spindle assembly checkpoint and aneuploidization in oral cancer. Carcinogenesis 2007, 28, 81-92. [CrossRef] [PubMed]

37. Hadjihannas, M.V.; Bernkopf, D.B.; Bruckner, M.; Behrens, J. Cell cycle control of Wnt/beta-catenin signalling by conductin/axin2 through Cdc20. EMBO Rep. 2012, 13, 347-354. [CrossRef] [PubMed]

38. Kidokoro, T.; Tanikawa, C.; Furukawa, Y.; Katagiri, T.; Nakamura, Y.; Matsuda, K. Cdc20, a potential cancer therapeutic target, is negatively regulated by p53. Oncogene 2008, 27, 1562-1571. [CrossRef] [PubMed]

39. Taniguchi, K.; Momiyama, N.; Ueda, M.; Matsuyama, R.; Mori, R.; Fujii, Y.; Ichikawa, Y.; Endo, I.; Togo, S.; Shimada, H. Targeting of Cdc20 via small interfering RNA causes enhancement of the cytotoxicity of chemoradiation. Anticancer Res. 2008, 28, 1559-1563. [PubMed]

40. Majumder, P.; Bhunia, S.; Bhattacharyya, J.; Chaudhuri, A. Inhibiting tumor growth by targeting liposomally encapsulated Cdc20 siRNA to tumor vasculature: Therapeutic RNA interference. J. Control. Release 2014, 180, 100-108. [CrossRef] [PubMed] 
41. Zeng, X.; Sigoillot, F.; Gaur, S.; Choi, S.; Pfaff, K.L.; Oh, D.C.; Hathaway, N.; Dimova, N.; Cuny, G.D.; King, R.W. Pharmacologic inhibition of the anaphase-promoting complex induces a spindle checkpoint-dependent mitotic arrest in the absence of spindle damage. Cancer Cell 2010, 18, 382-395. [CrossRef] [PubMed]

42. Sackton, K.L.; Dimova, N.; Zeng, X.; Tian, W.; Zhang, M.; Sackton, T.B.; Meaders, J.; Pfaff, K.L.; Sigoillot, F.; $\mathrm{Yu}, \mathrm{H}$.; et al. Synergistic blockade of mitotic exit by two chemical inhibitors of the APC/C. Nature 2014, 514, 646-649. [CrossRef] [PubMed]

43. Jiang, J.; Jedinak, A.; Sliva, D. Ganodermanontriol (GDNT) exerts its effect on growth and invasiveness of breast cancer cells through the down-regulation of Cdc20 and uPA. Biochem. Biophys. Res. Commun. 2011, 415, 325-329. [CrossRef] [PubMed]

44. Das, T.; Roy, K.S.; Chakrabarti, T.; Mukhopadhyay, S.; Roychoudhury, S. Withaferin a modulates the spindle assembly checkpoint by degradation of Mad2-Cdc20 complex in colorectal cancer cell lines. Biochem. Pharmacol. 2014, 91, 31-39. [CrossRef] [PubMed]

45. Zhang, L.; Niu, T.; Huang, Y.; Zhu, H.; Zhong, W.; Lin, J.; Zhang, Y. Compound 331 selectively induces glioma cell death by upregulating miR-494 and downregulating Cdc20. Sci. Rep. 2015, 5, 12003. [CrossRef] [PubMed]

46. Wang, L.; Hou, Y.; Yin, X.; Su, J.; Zhao, Z.; Ye, X.; Zhou, X.; Zhou, L.; Wang, Z. Rottlerin inhibits cell growth and invasion via down-regulation of Cdc20 in glioma cells. Oncotarget 2016, 7, 69770-69782. [CrossRef] [PubMed]

(C) 2017 by the authors; licensee MDPI, Basel, Switzerland. This article is an open access article distributed under the terms and conditions of the Creative Commons Attribution (CC BY) license (http:/ / creativecommons.org/licenses/by/4.0/). 